\title{
BMJ Open Cost-effectiveness analysis of arthroscopic surgery compared with non-operative management for osteoarthritis of the knee
}

\author{
Jacquelyn D Marsh, ${ }^{1}$ Trevor B Birmingham, ${ }^{2}$ J Robert Giffin, ${ }^{3}$ \\ Wanrudee Isaranuwatchai, ${ }^{4}$ Jeffrey S Hoch, ${ }^{5}$ Brian G Feagan, ${ }^{6}$ Robert Litchfield, ${ }^{3}$ \\ Kevin Willits, ${ }^{3}$ Peter Fowler ${ }^{3}$
}

To cite: Marsh JD, Birmingham TB, Giffin JR, et al. Cost-effectiveness analysis of arthroscopic surgery compared with non-operative management

for osteoarthritis of the knee. BMJ Open 2016;5:e009949. doi:10.1136/bmjopen-2015009949

- Prepublication history for this paper is available online. To view these files please visit the journal online (http://dx.doi.org/10.1136/ bmjopen-2015-009949).

Received 9 September 2015 Revised 27 November 2015 Accepted 10 December 2015

CrossMark

For numbered affiliations see end of article.

Correspondence to Dr Trevor B Birmingham; tbirming@uwo.ca and J Robert Giffin; rgiffin@uwo.ca

\section{ABSTRACT}

Objective: To determine the cost-effectiveness of arthroscopic surgery in addition to non-operative treatments compared with non-operative treatments alone in patients with knee osteoarthritis $(\mathrm{OA})$.

Design, setting and participants: We conducted an economic evaluation alongside a single-centre, randomised trial among patients with symptomatic, radiographic knee $\mathrm{OA}(\mathrm{KL}$ grade $\geq 2$ ).

Interventions: Patients received arthroscopic debridement and partial resection of degenerative knee tissues in addition to optimised non-operative therapy, or optimised non-operative therapy only.

Main outcome measures: Direct and indirect costs were collected prospectively over the 2-year study period. The effectiveness outcomes were the Western Ontario McMaster Osteoarthritis Index (WOMAC) and quality-adjusted life years (QALYs). Cost-effectiveness was estimated using the net benefit regression framework considering a range of willingness-to-pay values from the Canadian public payer and societal perspectives. We calculated incremental costeffectiveness ratios and conducted sensitivity analyses using the extremes of the $95 \%$ Cls surrounding mean differences in effect between groups.

Results: 168 patients were included. Patients allocated to arthroscopy received partial resection and debridement of degenerative meniscal tears $(81 \%)$ and/or articular cartilage $(97 \%)$. There were no significant differences between groups in use of nonoperative treatments. The incremental net benefit was negative for all willingness-to-pay values. Uncertainty estimates suggest that even if willing to pay $\$ 400000$ to achieve a clinically important improvement in WOMAC score, or $\geq \$ 50000$ for an additional QALY, there is $<20 \%$ probability that the addition of arthroscopy is cost-effective compared with nonoperative therapies only. Our sensitivity analysis suggests that even when assuming the largest treatment effect, the addition of arthroscopic surgery is not economically attractive compared with nonoperative treatments only.

Conclusions: Arthroscopic debridement of degenerative articular cartilage and resection

\section{Strengths and limitations of this study}

- This randomised trial-based economic evaluation prospectively collected clinical effectiveness and cost measures, including indirect patientreported costs, and directly elicited utility scores from patients over a 2-year follow-up with minimal loss to follow-up or crossovers.

- Our estimation of cost-effectiveness over a range of willingness-to-pay values, investigation of patient subgroups, and analysis of uncertainty suggests that arthroscopy is not cost-effective compared with non-operative care, as the additional costs of surgery are not offset by decreases in other direct or indirect costs associated with knee $\mathrm{OA}$.

- These results add important economic data to the existing clinical evidence refuting the value of arthroscopic debridement and resection of degenerative knee tissues.

- The present results do not describe the costeffectiveness of knee arthroscopy beyond 2 years of surgery; however, previous research consistently shows that any small additional benefits observed with arthroscopic surgery for degenerative knee conditions diminish by 1 year, suggesting it is unlikely for arthroscopy to become cost-effective as time progresses.

- As the present study was designed to evaluate the cost-effectiveness of arthroscopy for patients with knee $O A$, conclusions about the costeffectiveness of one non-operative treatment compared with another (including sham), or among patients without radiographic signs of $O A$ should not be drawn from the present data.

of degenerative meniscal tears in addition to nonoperative treatments for knee $\mathrm{OA}$ is not an economically attractive treatment option compared with non-operative treatment only, regardless of willingnessto-pay value.

Trial registration number: NCT00158431. 


\section{INTRODUCTION}

Osteoarthritis $(\mathrm{OA})$ of the knee is a leading cause of disability and healthcare use globally, and the substantial economic burden is expected to grow. ${ }^{1}{ }^{2}$ Knee OA is a progressive condition that affects the whole joint, including degenerative changes to the menisci, bone and hyaline articular cartilage. ${ }^{34}$ Clinical practice guidelines for managing knee OA consistently recommend nonoperative therapies as first-line treatments, ${ }^{5-9}$ yet recommendations are less clear for the additional role of arthroscopic surgical interventions such as trimming meniscal tears to a stable rim (ie, partial resection), smoothing articular surfaces (ie, debridement) and removing loose bodies and/or osteophytes; procedures that are still widely used to treat these degenerative joint changes.

We previously conducted a randomised controlled trial evaluating the effectiveness of arthroscopic surgery in addition to optimised physical and medical therapy among patients with symptomatic, radiographic knee OA over a 2-year period. ${ }^{10}$ Results showed that arthroscopy provided no additional benefit beyond 3 months from surgery. Similarly, additional randomised trials involving different intervention strategies and increasingly restrictive eligibility criteria have also evaluated arthroscopic surgery for degenerative changes in the knee. These trials include arthroscopy compared with sham surgery in patients with moderate-to-severe radiographic OA, ${ }^{11}$ arthroscopic partial meniscectomy compared with physical therapy and exercise in patients with mild-to-moderate radiographic $\mathrm{OA}^{12}{ }^{13}$ and arthroscopic partial meniscectomy compared with nonoperative management ${ }^{14}{ }^{15}$ or to sham surgery $^{16}$ in patients with degenerative meniscal tears and no radiographic evidence of OA. Meta-analyses of the existing evidence conclude that the additional benefit observed after arthroscopy compared with non-operative interventions is limited in time and absent at $1-2$ years after surgery. ${ }^{17} 18$

Despite this evidence, arthroscopic knee procedures are still commonly performed. While administrative data suggest rates of arthroscopy for knee OA are declining, the number of procedures performed annually remains high and the rate of arthroscopies to treat meniscal tears, a common feature of knee $\mathrm{OA},{ }^{3}$ has remained the same or increased. ${ }^{19-26}$ Accordingly, the role of arthroscopic surgery for treating degenerative knee conditions remains highly debated. ${ }^{27-29}$

Although studies demonstrating a lack of clinical effectiveness may suggest an economic evaluation is unnecessary, many authors strongly caution against abandoning the procedure, stating the improvements observed after surgery despite being similar to nonoperative treatments or to sham treatments are clinically important and considered cost-effective nonetheless. ${ }^{27} 28$ 30-32 Therefore, it is clear that evidence regarding the cost-effectiveness of knee arthroscopy would be valuable and analysis of the existing trial-based economic data is warranted. The purpose of the present study was to determine the cost-effectiveness of arthroscopic surgery in addition to non-operative treatments compared with non-operative treatments alone in patients with knee OA.

\section{METHODS}

\section{Randomised controlled trial}

The present data were collected as part of our previously reported single-centre, randomised controlled trial. ${ }^{10}$ Patients with symptomatic, radiographic knee OA were randomly assigned to knee arthroscopy in addition to optimised physical and medical therapy, or to optimised physical and medical therapy only. Patients were evaluated at baseline and 3, 6, 12, 18 and 24 months after the initiation of treatment. The protocol was approved by our institution's research ethics board, and all participants gave written informed consent.

Optimised physical and medical therapy included a $1 \mathrm{~h}$ physical therapy session once a week for 12 consecutive weeks, an individualised home exercise programme, and education from the local Arthritis Society. ${ }^{33}$ Patients reviewed their medical treatment plans with their orthopaedic surgeon, optimised according to an evidencebased treatment algorithm consistent with published guidelines. $^{34}$

Patients in the surgery group received arthroscopy within 6 weeks of randomisation. The specific surgical procedures have been previously described. ${ }^{10}$ Patients followed the same optimised physical and medical therapy programme as those in the non-operative group, beginning within 7 days following surgery.

\section{Outcome measures}

We conducted our cost-effectiveness analyses using two separate patient-reported outcomes as our measure of effectiveness. First, we used the Western Ontario McMaster Osteoarthritis Index (WOMAC) total score at the 2-year follow-up (the primary outcome from the randomised trial). Total scores can range from 0 to 2400, with higher scores indicating increased pain and stiffness, and decreased physical function. ${ }^{35-37}$ We rescaled the scores so that a higher number indicated a better outcome. Published data suggested similar patients typically have a total WOMAC score of 1000 points. ${ }^{38}$ We considered a 20\% improvement from this score (about 200 points) as clinically important. ${ }^{10}$

Our second effectiveness measure was quality-adjusted life years (QALYs). ${ }^{39}{ }^{40}$ We calculated QALYs using the Standard Gamble technique. ${ }^{41}$ The Standard Gamble is a health utility measure, with scores ranging from 0.0 (death) to 1.0 (perfect health). QALY is calculated as the product of the utility score and the duration of the corresponding health state. We report QALY over the 2-year study time period. 


\section{Costs}

\section{Arthroscopy}

We used the average procedure cost from the Ontario Case Costing Initiative ${ }^{42}$ to obtain the direct costs of each procedure including equipment, operating room costs, and laboratory or other medical tests during the procedure. We used the current surgeon billing fee for each procedure listed in the Ontario Schedule of Benefits. $^{43}$

\section{Non-operative care}

We recorded the number of physical therapy sessions attended for each patient. We used the rate per session provided by a local physical therapy clinic. We also recorded any medication use, including both over-the-counter and prescription pain or antiinflammatory drugs, hyaluronic acid injections or other medical treatment for knee OA. Unit costs for drugs were obtained from the Ontario Drug Benefit Formulary. ${ }^{44}$ Patients reported the amount paid for any aids purchased for the study knee, such as orthotics, crutches or braces.

\section{Other healthcare costs}

At each of the 3, 6, 12, 18 and 24 months of follow-up visits, we recorded healthcare resource use associated with the study knee including inpatient hospitalisations, physical therapy, medication use (prescription and over-the-counter), assistive devices, employment time lost, and homemaking or volunteer time lost.

We estimated the total cost for each patient over the entire study period. All costs are presented in 2014 Canadian dollars.

\section{Statistical analysis}

We conducted a cost-effectiveness analysis from both the Canadian healthcare payer and societal perspectives. The payer perspective includes direct costs covered by the publicly funded system, including hospital, procedure-related, clinician and provider time, tests, procedures or surgeries, and medications for patients on disability or aged 65 years and older. In addition to the healthcare system costs, the societal perspective also includes any out-of-pocket costs to the patient (such as physical therapy, medication or assistive devices not covered by the provincial insurance plan), and indirect costs such as time involved with appointments, and time off employment, homemaking or caregiving activities as a result of the intervention.

\section{Net benefit regression}

The net benefit regression (NBR) framework ${ }^{45}$ provides an estimate of cost-effectiveness by considering the incremental cost and effect on an intervention in addition to the maximum acceptable willingness-to-pay (WTP) per unit of health gain; in this case, WTP refers to the amount one is willing to spend for an additional improvement on the WOMAC score, or for an additional
QALY gained. An intervention is cost-effective if the incremental net benefit (INB) is greater than zero.

We conducted two separate NBR models, the first using the WOMAC total score, and the second using QALYs as the measure of effectiveness. The WTP value was varied between $\$ 0$ and $\$ 100000$. Although we anticipated that the randomised allocation of participants would result in an equal distribution of baseline characteristics between groups, the NBR method provides a means to adjust for any potentially confounding factors and therefore allows greater statistical efficiency and provides a more precise estimate of the INB.

We included the following covariates in our models: baseline WOMAC score, baseline utility (for the QALY model), radiographic severity of knee OA (KellgrenLawrence grade 2, or greater than 2), age and body mass index. Significant covariates from our regression model were also included as interaction terms.

Statistical uncertainty was characterised using 95\% CIs, and visually displayed using the cost-effectiveness plane, and cost-effectiveness acceptability curves (CEAC). ${ }^{46}$ We used non-parametric bootstrapping to draw 1000 incremental cost-effectiveness ratio (ICER) estimates from the original sample, and plotted them on the costeffectiveness plane. The CEAC demonstrates the probability of cost-effectiveness at various WTP values.

\section{Subgroup analysis}

We repeated the two subgroup analyses performed in the original trial, among the two groups of patients that were hypothesised to derive greater benefit from surgery: (1) patients with less severe radiographic disease (KL grade 2), and (2) patients reporting mechanical symptoms of catching and/or locking. ${ }^{10}$

\section{ICER, incremental cost-utility ratio and sensitivity analysis}

We also considered the value of arthroscopy by calculating the ICERs. Further, we conducted a sensitivity analysis by using either extreme of our CI surrounding the mean difference in WOMAC scores and QALY to estimate ICER and incremental cost-utility ratio (ICUR) values that assumed the highest possible treatment effect observed in our sample, favouring either added arthroscopy or non-operative treatments only.

\section{RESULTS}

A total of 168 patients were included (88 arthroscopy group and 80 non-operative group; figure 1). Baseline characteristics of the study participants were similar between groups (table 1). Patients allocated to the arthroscopy group received debridement of degenerative articular cartilage $(97 \%)$, partial resection of degenerative meniscal tears $(81 \%)$, excision of osteophytes $(9 \%)$ and removal of loose bodies (14\%). Non-operative treatment included medical therapy (non-steroidal anti-inflammatory drugs, acetaminophen, chondroitin 


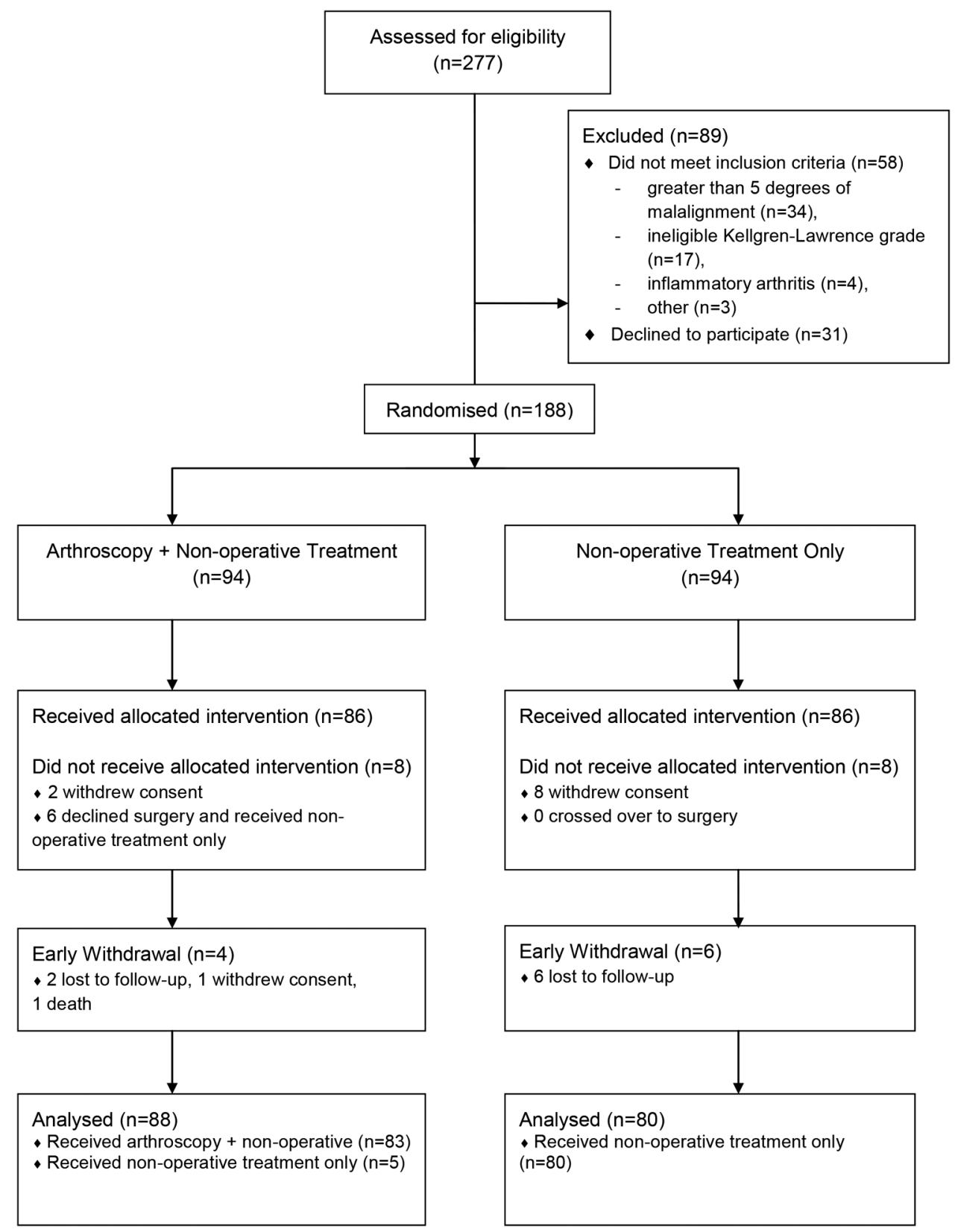

Figure 1 Participant flow diagram.

sulfate or glucosamine, hyaluronic acid injection), physical therapy and bracing. There were no significant differences in non-operative treatment between groups (table 1).

There was a statistically significant difference between groups in mean costs from both the healthcare payer and societal perspectives (table 2). The mean difference between groups in WOMAC scores at 24 months was small (favouring the surgery group) and not statistically significant (mean difference $=15.69$ ( -198.58 to 166.98$)$, $\mathrm{p}=0.87$ ). The mean difference between groups in QALY scores was also small (favouring the non-operative treatments only group) and not significantly different (mean difference $=-0.02,95 \%$ CI -0.09 to $0.13, \mathrm{p}=0.72$; table 2).

\section{Net benefit regression}

Model 1: WOMAC

The INB was negative for all WTP values, from both the healthcare payer and societal perspectives, indicating that the addition arthroscopic surgery is not costeffective compared with non-operative treatments only (table 3).

\section{Model 2: QALY}

When using QALYs as the outcome, the INB estimate was also negative at all WTP values, further suggesting that the addition arthroscopic surgery is not costeffective compared with non-operative treatments only (table 3). 
Table 1 Baseline characteristics of participants and interventions

\begin{tabular}{|c|c|c|}
\hline Characteristic & $\begin{array}{l}\text { Arthroscopic } \\
\text { surgery }(n=88)\end{array}$ & $\begin{array}{l}\text { Non-operative } \\
(n=80)\end{array}$ \\
\hline Male-n (\%) & $34(39)$ & $23(28)$ \\
\hline Age (years) ${ }^{\star}$ & $58.3 \pm 9.8$ & $60.5 \pm 9.9$ \\
\hline Body mass index $†$ & $31.6 \pm 6.6$ & $30.2 \pm 6.4$ \\
\hline \multicolumn{3}{|l|}{ Kellgren-Lawrence grade-n (\%) $\ddagger$} \\
\hline 2 & $42(48)$ & $34(42)$ \\
\hline 3 & $41(47)$ & $42(53)$ \\
\hline 4 & $5(6)$ & $4(5)$ \\
\hline Symptoms of catching or locking-n (\%) & $43(49)$ & $37(46)$ \\
\hline WOMAC total score* & $1222.9(478.2)$ & $1354.1(545.5)$ \\
\hline SG utility score & $0.79(0.22)$ & $0.80(0.21)$ \\
\hline \multicolumn{3}{|l|}{ Non-operative treatment-n (\%) } \\
\hline \multicolumn{3}{|l|}{ Medical therapy } \\
\hline Non-steroidal anti-inflammatory drugs & $53(58)$ & $48(56)$ \\
\hline Acetaminophen & $53(58)$ & $43(50)$ \\
\hline Chondroitin sulfate or glucosamine & $28(30)$ & $25(29)$ \\
\hline Hyaluronic acid injection & $39(42)$ & $33(38)$ \\
\hline Physical therapy§ & $9.3 \pm 5.1$ & $8.0 \pm 5.7$ \\
\hline Use of brace & $3(3)$ & $5(6)$ \\
\hline \multicolumn{3}{|l|}{ Surgical treatment-n (\%) } \\
\hline Debridement of articular cartilage & $83(97)$ & \\
\hline Debridement or partial resection of meniscus & $70(81)$ & \\
\hline Excision of osteophytes & $8(9)$ & \\
\hline Removal of loose bodies & $12(14)$ & \\
\hline \multicolumn{3}{|c|}{$\begin{array}{l}\text { "Mean (SD). } \\
\text { †Body mass index is the weight in kilograms divided by the square of the height in metres. } \\
\text { †Scale that evaluates the radiographic severity of osteoarthritis. } \\
\text { §Average number of physical therapy sessions attended in the first } 3 \text { months since randomisation. } \\
\text { SG, Standard Gamble; WOMAC, Western Ontario and McMaster Universities Osteoarthritis Index. }\end{array}$} \\
\hline
\end{tabular}

\section{Subgroup analysis}

Arthroscopy was also not cost-effective in terms of both WOMAC and QALY in the subgroup of patients with less severe disease (Kellgren-Lawrence grade 2) and patients reporting mechanical symptoms of catching and/or locking from both cost perspectives at all values of WTP.

\section{ICER, ICUR and sensitivity analysis}

The ICER was $\$ 140.94$ (societal), or $\$ 120.83$ (payer) per one-point improvement on the 2400 point WOMAC total score, translating to \$28 188 (societal) and \$24166 (payer) for a clinically important improvement (200 points). The ICUR was equal to $-\$ 110569$ (societal) or -\$94792.50 (payer) per QALY gained, where the negative value indicates paying more for a worse outcome (ie, the added surgery is dominated by non-operative treatments only).

The results of our sensitivity analysis using either extreme of our CIs suggested that, from the societal perspective, to achieve a clinically important improvement

Table 2 Cost and effect outcomes

\begin{tabular}{|c|c|c|c|}
\hline & Surgery* & Non-operative* & Incremental difference† \\
\hline \multicolumn{4}{|l|}{ WOMAC } \\
\hline Baseline & $1222.91(478.16)$ & $1355.26(548.92)$ & -132.35 ( -24.58 to 289.29$), 0.10$ \\
\hline 24-month & $1526.45(623.83)$ & $1510.77(570.21)$ & $15.69(-198.35$ to 166.98$), 0.87$ \\
\hline \multicolumn{4}{|l|}{ Utility } \\
\hline Baseline & $0.79(0.22)$ & $0.80(0.21)$ & $0.01(-0.06$ to 0.07$), 0.85$ \\
\hline 24-month & $0.84(0.23)$ & $0.86(0.16)$ & $0.02(-0.04$ to 0.08$), 0.47$ \\
\hline QALY & $1.64(0.40)$ & $1.66(0.30)$ & $-0.02(-0.09$ to 0.13$), 0.72$ \\
\hline \multicolumn{4}{|l|}{ Costł } \\
\hline Healthcare payer perspective & $2633.25(574.43)$ & $737.40(542.93)$ & 1895.85 (1716.13 to 2075.57$),<0.01$ \\
\hline Societal perspective & $3825.60(1443.48)$ & $1614.22(1784.94)$ & 2211.38 (1716.04 to 2706.51$),<0.01$ \\
\hline \multicolumn{4}{|c|}{$\begin{array}{l}\text { *Mean (SD). } \\
\text { †Mean difference between groups }(95 \% \mathrm{Cl}), \mathrm{p} \text { value. } \\
\ddagger 2014 \text { Canadian dollars. } \\
\text { QALY, quality-adjusted life year; WOMAC, Western Ontario and McMaster Universities Osteoarthritis Index. }\end{array}$} \\
\hline
\end{tabular}




\begin{tabular}{|c|c|c|c|c|}
\hline \multicolumn{5}{|c|}{ (A) WOMAC } \\
\hline \multirow[b]{2}{*}{ WTP* } & \multicolumn{2}{|l|}{ Healthcare payert } & \multicolumn{2}{|l|}{ Societal† } \\
\hline & Incremental net benefit & $95 \% \mathrm{Cl}, \mathrm{p}$ value & Incremental net benefit & $95 \% \mathrm{Cl}, \mathrm{p}$ value \\
\hline 0 & $-1179.20(386.56)$ & -1942.58 to $-415.82,<0.01$ & -1670.507 (662.18) & -2978.30 to $-362.71,0.01$ \\
\hline 1500 & $-352418.73(332804.27)$ & -1009643.31 to $304805.85,0.29$ & -369151.74 (334686.56) & -1030156.42 to $291852.95,0.27$ \\
\hline 2000 & $-469498.57(443753.31)$ & -1345826.20 to $406829.05,0.29$ & $-491645.48(446248.44)$ & -1372984.45 to $389693.49,0.27$ \\
\hline 2500 & $-586578.42(554702.36)$ & -1682009.13 to $508852.29,0.29$ & $-614139.22(557810.37)$ & -1715812.60 to $487534.16,0.27$ \\
\hline 5000 & $-1171977.63(1109447.72)$ & -3362923.98 to $1018968.72,0.29$ & $-1226607.94(1115620.38)$ & -3429953.97 to $976738.10,0.27$ \\
\hline 10000 & $-2342776.07(2218938.56)$ & -6724753.89 to $2039201.76,0.29$ & $-2451545.36(2231240.70)$ & -6858237.29 to $1955146.56,0.27$ \\
\hline 20000 & $-4684372.93(4437920.28)$ & -13448413.80 to $4079667.94,0.29$ & $-4901420.22(4462481.46)$ & -13714804.20 to $3911963.77,0.27$ \\
\hline 30000 & $-7025969.80(6656902.01)$ & -20172073.70 to $6120134.15,0.29$ & -7351295.08 (6693722.26) & -20571371.20 to $5868871.04,0.27$ \\
\hline 40000 & $-9367566.66(8875883.74)$ & -26895733.70 to $8160600.36,0.29$ & $-9801169.94(8924963.07)$ & -27427938.20 to $7825598.33,0.27$ \\
\hline 50000 & $-11709163.50(11094865.47)$ & -33619393.60 to $10201066.58,0.29$ & $-12251044.80(11156203.89)$ & -34284505.20 to $9782415.63,0.27$ \\
\hline 60000 & $-14050760.40(13313847.20)$ & -40343053.60 to $12241532.79,0.29$ & -14700919.70 (13387444.70) & -41141072.20 to $11739232.93,0.27$ \\
\hline 70000 & $-16392357.30(15532828.94)$ & -47066713.50 to $14281999.01,0.29$ & $-17150794.50(15618685.51)$ & -47997639.20 to $13696050.23,0.27$ \\
\hline 80000 & $-18733954.10(17751810.67)$ & -53790373.50 to $16322465.23,0.29$ & -19600669.40 (17849926.33) & -54854206.30 to $15652867.53,0.27$ \\
\hline 90000 & $-21075551.00(19970792.40)$ & -60514033.40 to $18362931.44,0.29$ & $-22050544.20(20081167.14)$ & -61710773.30 to $17609684.84,0.27$ \\
\hline 100000 & $-23417147.90(22189774.14)$ & -67237693.40 to $20403397.66,0.29$ & $-24500419.10(22312407.96)$ & -68567340.30 to $19566502.14,0.27$ \\
\hline \multicolumn{5}{|c|}{ (B) QALY } \\
\hline \multirow[b]{2}{*}{ WTP } & \multicolumn{2}{|l|}{ Healthcare payert } & \multicolumn{2}{|l|}{ Societalt } \\
\hline & Incremental net benefit & $95 \% \mathrm{Cl}, \mathrm{p}$ value & Incremental net benefit & $95 \% \mathrm{Cl}, \mathrm{p}$ value \\
\hline 0 & $-2020.18(558.61)$ & -3123.38 to $-916.98,<0.01$ & $-2048.89(946.17)$ & -3917.66 to $-180.11,0.03$ \\
\hline 1500 & $-2226.59(608.74)$ & -3427.75 to $-1023.38,<0.01$ & $-2250.38(1006.93)$ & -4239.15 to $-261.59,0.03$ \\
\hline 2000 & $-2294.02(645.94)$ & -3569.69 to $-1018.34,<0.01$ & $-2317.54(1039.73)$ & -4371.10 to $-263.98,0.03$ \\
\hline 2500 & $-2362.48(691.03)$ & -3727.19 to $-997.77,<0.01$ & $-2384.70(1077.94)$ & -4513.73 to $-255.67,0.03$ \\
\hline 5000 & $-2704.77(991.35)$ & -4662.60 to $-746.96,0.01$ & $-2720.52(1331.67)$ & -5350.69 to -90.340 .04 \\
\hline 10000 & $-3389.38(1735.70)$ & -6817.21 to $38.45,0.05$ & $-3392.14(2007.52)$ & -7357.19 to $572.91,0.09$ \\
\hline 20000 & -4758.57 (3339.13) & -11353.01 to $1835.87,0.16$ & $-4735.40(3560.87)$ & -11768.45 to $2297.66,0.18$ \\
\hline 30000 & $-6127.77(4972.26)$ & -15947.50 to $3691.96,0.22$ & $-6078.65(5181.15)$ & -16311.90 to $4154.60,0.24$ \\
\hline 40000 & $-7496.98(6613.14)$ & -20557.26 to $5563.32,0.26$ & $-7452.72(6820.82)$ & -20893.66 to $6049.85,0.28$ \\
\hline 50000 & -8866.17 (8257.13) & -25173.19 to $7440.86,0.29$ & -8765.16 (8468.63) & -25491.49 to $7961.16,0.30$ \\
\hline 60000 & $-10235.37(9902.70)$ & -29792.22 to $9321.50,0.30$ & $-10108.42(10120.60)$ & -30097.54 to $9880.70,0.32$ \\
\hline 70000 & $-11604.56(11549.16)$ & -34413.03 to $11203.90,0.32$ & $-11451.68(11774.98)$ & -34708.34 to $11804.99,0.33$ \\
\hline 80000 & $-12973.76(13196.19)$ & -39034.94 to $13087.42,0.33$ & $-12794.93(13430.88)$ & -39322.15 to $13732.30,0.34$ \\
\hline 90000 & $-14342.96(14843.59)$ & -43657.60 to $14971.67,0.34$ & $-14138.19(15087.81)$ & -43937.98 to $15661.62,0.35$ \\
\hline 100000 & $-15712.16(16491.26)$ & -48280.77 to $16856.45,0.34$ & $-15481.44(16745.45)$ & -48555.23 to $17592.53,0.36$ \\
\hline
\end{tabular}


of 200 WOMAC points, either: (1) assuming the added surgery results in an improvement over non-operative treatments only (167 WOMAC points), the cost is an additional $\$ 2648$, or (2) assuming non-operative treatments result in an improvement over added surgery (-199 WOMAC points), the ICER is $-\$ 2230$, resulting in paying more to achieve a worse outcome. Additionally, for QALY, the sensitivity analysis suggests either: (1) an ICUR of $\$ 17010$, where surgery costs an additional \$16 961 per QALY gained, or (2) an ICUR of -\$24 571 where surgery costs more and is less effective.

\section{Uncertainty}

The $95 \%$ CIs around our estimate of INB get wider as the WTP value increases, suggesting that the more one is willing to pay, the greater the uncertainty surrounding the cost-effectiveness.

The uncertainty is also visually displayed on the costeffectiveness plane (figure 2). Although the majority of the bootstrapped estimates suggest a greater improvement in WOMAC score for the added surgery group, very few represent a clinically important improvement (200 points; figure 2A); whereas for QALY, about $60 \%$ of the ICUR estimates favour a greater improvement for the non-operative treatments only group (figure $2 \mathrm{~B}$ ). In both cases, there is no uncertainty surrounding the cost (surgery always costs more); therefore, decision makers face the risk of paying more for a treatment with considerable uncertainty that it will result in improved outcome.

The probability of cost-effectiveness given this uncertainty is visually displayed in the CEAC (figure 3). This suggests that even if decision makers are willing to pay $\$ 2000$ or more for a one-point improvement on the WOMAC total score (figure 3A; translating into $\$ 400000$ to achieve a clinically important difference), or $\$ 50000$ or more for an additional QALY (figure $3 \mathrm{~B})$, there is less than a $20 \%$ probability that added surgery is cost-effective compared with non-operative care only.

\section{DISCUSSION}

The results of the present analysis suggest that arthroscopic debridement and partial resection of degenerative knee tissues performed in addition to optimised physical and medical therapy for patients with knee OA is not cost-effective compared with optimised physical and medical therapy only, from both a healthcare payer and societal perspective. This conclusion is driven by the finding that although there is statistical uncertainty about which treatment is more effective (ie, in our sample a small improvement could favour either treatment), the additional cost of surgery is not offset by decreases in other healthcare costs, either direct or indirect, associated with knee OA. Specifically, there were no differences between groups in the use of nonoperative treatments, and a greater proportion of
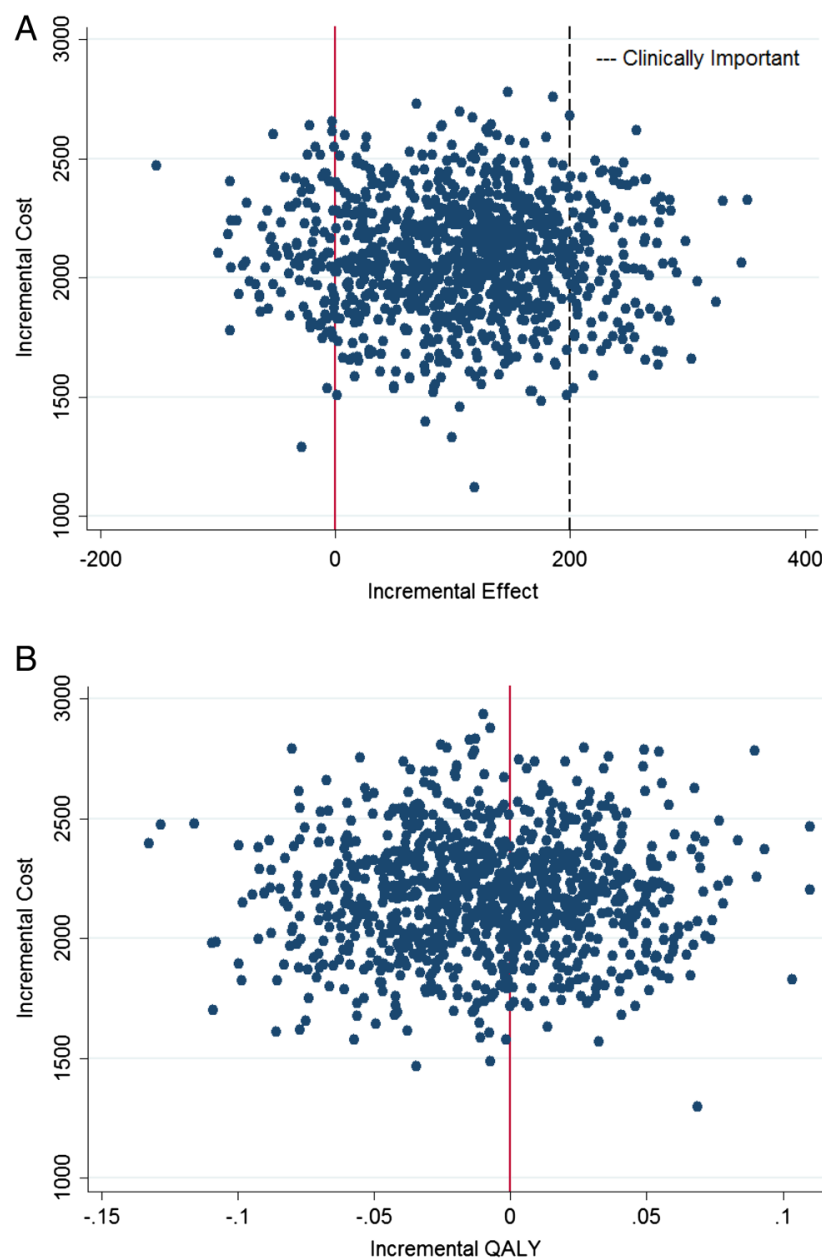

Figure 2 (A) The y-axis represents the incremental cost (mean cost of arthroscopy group-mean cost of non-operative group) in 2014 Canadian dollars. The $\mathrm{x}$-axis represents the mean difference in WOMAC total score at 2-year follow-up between groups. The plotted values represent 1000 bootstrap estimates of incremental cost-effectiveness ratios. (B) The $\mathrm{y}$-axis represents the incremental cost (mean cost of arthroscopy group-mean cost of non-operative group) in 2014 Canadian dollars. The $\mathrm{x}$-axis represents the mean difference in quality-adjusted life years (QALYs) between groups. The plotted values represent 1000 bootstrap estimates of incremental cost-effectiveness ratios.

patients in the surgery group reported taking time off work at the 3-month follow-up.

Strengths of the present economic evaluation include data collected from a prospective randomised trial with frequent assessments over a 2-year follow-up and minimal loss to follow-up or crossovers. ${ }^{10}$ This enabled a rigorous trial-based economic evaluation with prospective collection of effectiveness and cost measures (including indirect patient-reported costs), and the direct measurement of utility scores from our study patients to calculate QALYs. Further, using the NBR framework allowed us to include potential interaction terms, explore patient subgroups and evaluate the data for influential outliers to provide us with a clearer 
Figure 3 The y-axis represents the probability that arthroscopy is cost-effective compared with non-operative treatment. The $x$-axis represents the amount one is willing to pay to achieve an improvement in outcome $((\mathrm{A})$ one-point improvement on Western Ontario and McMaster Universities Osteoarthritis Index (WOMAC) total score, (B) one additional quality-adjusted life year).

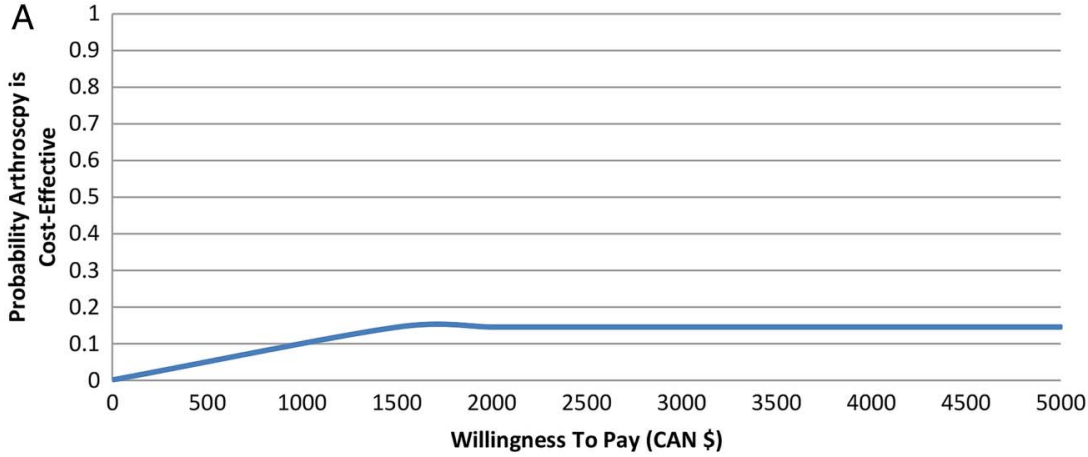

B

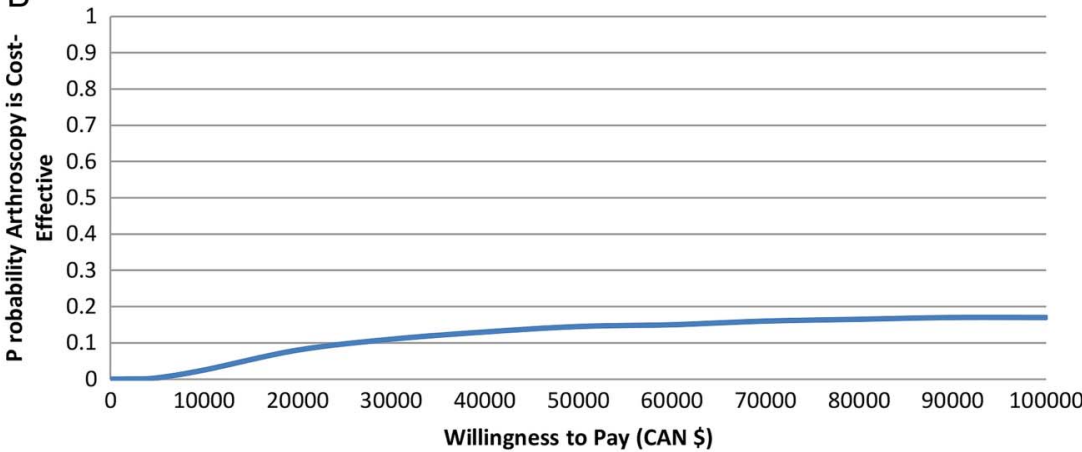

understanding of the cost-effectiveness than would have been possible by only looking at the incremental ratios. ${ }^{45}$

Limitations of this trial-based economic analysis may include the inability to determine long-term costeffectiveness beyond 2 years of follow-up. However, previous research consistently shows that any small additional benefits observed with arthroscopic surgery for degenerative knee conditions diminish by 1 year; ${ }^{10-14} 16$ therefore, we suggest it is unlikely for arthroscopy to become cost-effective as time progresses. Reports of increased risk for $\mathrm{OA}^{47-49}$ and earlier joint replacement ${ }^{50}$ after meniscectomy should also be considered when evaluating long-term cost-effectiveness. As the present study was designed to evaluate the cost-effectiveness of arthroscopy in addition to non-operative care for patients with radiographic knee OA (KL grade $\geq 2$ ), results should be generalised accordingly. Conclusions about the clinical and cost-effectiveness of the various non-operative treatments, and the cost-effectiveness of arthroscopy for patients without radiographic knee OA, should not be drawn from the present data. Additionally, the present sample does not include persons suspected by the surgeon based on physical examination and history to have a traumatic bucket handle meniscal tear (ie, acute knee injury, swelling, acute loss of knee extension). Unlike degenerative meniscal tears, bucket handle tears are not common in knee OA and form a different patient population. Importantly, the present results are generalisable to the many patients with degenerative knees receiving knee arthroscopy. ${ }^{24-26}$ Notably, operative data from our trial suggest that, as anticipated, more than $80 \%$ of patients had degenerative meniscal tears that were partially resected.
Some suggest that arthroscopic debridement and resection is beneficial for appropriately selected patients with knee OA, such as those with minimal radiographic changes and symptoms consistent with a torn meniscus. Approximately, half of our sample would be classified by accepted criteria as having mild OA (Kellgren-Lawrence grade 2). Approximately, half of our sample reported symptoms of catching and/or locking. We reported in our original trial no added benefit of surgery among the subgroup of patients with mild OA, or among the subgroup of patients with symptoms of catching and/or locking. Similarly, the present results suggest that arthroscopy is also not cost-effective for those subgroups of patients compared with non-operative management. The lack of clinical effectiveness in those subgroups is consistent with meta-analysis of the randomised trials evaluating arthroscopic partial meniscectomy in the degenerative knee, ${ }^{17}$ including a sham controlled trial in middle-aged patients with degenerative meniscal tears in the absence of radiographic knee OA. ${ }^{18}$

To our knowledge, this is the first trial-based economic evaluation to evaluate the cost-effectiveness of knee arthroscopy in addition to non-operative treatment strategies. Lubowitz and Appleby ${ }^{32}$ reported the total procedure costs for a range of arthroscopic procedures and the change in utility score before and after surgery; however, they did not compare arthroscopic surgery to other interventions. Alternatively, Losina $e t a l^{30}$ built a probabilistic state-transition model to evaluate the costeffectiveness of arthroscopic surgery over a 10-year life span for patients with knee OA. The model compared immediate arthroscopic surgery, physical therapy and delayed arthroscopic surgery (patients electing to 
undergo surgery after 3 months of physical therapy). The clinical and economic input parameters were derived from a previous randomised trial ${ }^{12}$ (including crossovers from physical therapy to surgery) using patient-reported outcomes up to 6 months following treatment, and from large cohort studies in the USA to determine rates of progression of OA. The authors conclude that physical therapy alone is unlikely to be costeffective and suggest further research is required to determine the cost-effectiveness of immediate arthroscopy or arthroscopy following a course of physical therapy. Although differences in study design, treatment protocols and settings may contribute to their findings, that study contrasts the present results in which there were no differences in patient-reported outcomes, healthcare resource use following treatment or productivity losses between groups over a 2-year follow-up.

Several factors likely contribute to the continued frequent use of arthroscopic debridement and resection of degenerative knee tissues for knee OA. ${ }^{26}$ The unnecessary use of MRI to diagnose degenerative meniscal tears, early referral to orthopaedic surgeons, vested interests and the evident placebo effect of surgery all likely contribute to high patient and clinician expectations and demand for the procedure. The variable increases in rates of arthroscopy among different regions and previously observed shifts in practice after publication of research findings suggest that knowledge translation activities can affect knee arthroscopy usage ${ }^{19-26}$ We suggest that such activities should include cost-effectiveness data in addition to clinical effectiveness data and target patients, all clinicians involved in their care, as well as policymakers.

The preponderance of evidence suggests that arthroscopic debridement in the degenerative knee is not superior to sham surgery, provides no sustained clinical benefit over non-operative treatments and is associated with potential harms. ${ }^{17}$ In addition to the lack of clinical effectiveness, the present results suggest that arthroscopic debridement of degenerative articular cartilage and resection of degenerative meniscal tears in addition to non-operative treatment for knee $\mathrm{OA}$ is not an economically attractive treatment option compared with non-operative treatment only.

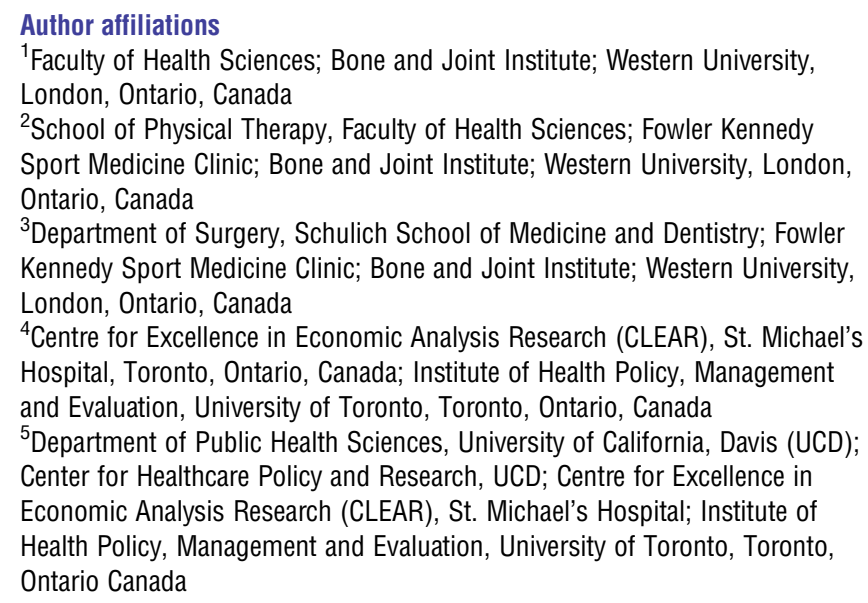

${ }^{6}$ Departments of Medicine, and Epidemiology and Biostatistics, Schulich School of Medicine and Dentistry; Robarts Clinical Trials, Robarts Research Institute; Western University, London, Ontario, Canada

Contributors All authors had full access to all of the data in the study and take responsibility for the integrity of the data and the accuracy of the data analysis. TBB, JRG, BGF, RL, KW and PF were involved in study concept and design. JDM, WI, JSH and TBB were involved in analysis and interpretation of data. JDM, TBB, WI and JSH drafted the manuscript. JDM, TBB, WI, JSH, JRG, BGF, RL, KW and PF were involved in revision of manuscript.

Funding This research was undertaken, in part, thanks to funding from the Canadian Institutes of Health Research, The Ontario Ministry of Research and Innovation, and The Canada Research Chairs Programme.

Competing interests All authors have completed the ICMJE uniform disclosure form at http://www.icmje.org/coi_disclosure.pdf and declare: support from The Canadian Institutes of Health Research for the submitted work; TBB reports grants from Canada Research Chairs Program, during the conduct of the study; grants from The Canadian Institutes of Health Research, grants from The Arthritis Society, grants from Arthrex Inc, outside the submitted work; JRG reports grants from The Canadian Institutes of Health Research, grants from The Arthritis Society, grants from Arthrex Inc, outside the submitted work; KW reports grants from Arthrex Inc, outside the submitted work; RL reports personal fees from Arthrosurface, personal fees from Smith \& Nephew, personal fees from DePuy, grants from Smith \& Nephew, grants from DePuy, outside the submitted work; BGF reports grants and personal fees from AbbVie, personal fees from Actogenix, personal fees from Akros, personal fees from Albireo, grants and personal fees from Amgen, grants and personal fees from Astra Zeneca, personal fees from Avaxia Biologics, personal fees from Avir Pharma, personal fees from Baxter Healthcare Corp, personal fees from Biogen Idec, personal fees from Boehringer-Ingelheim, grants and personal fees from Bristol-Meyers Squibb, personal fees from Calypso Biotech, personal fees from Celgene, personal fees from Elan/Biogen, personal fees from EnGene, personal fees from Ferring Pharma, grants and personal fees from Roch/Genetech, personal fees from GiCare Pharma, personal fees from Gilead, personal fees from Given Imaging, personal fees from GSK, personal fees from Ironwood Pharma, grants and personal fees from JnJ/Janssen, personal fees from Kyowa Kakko Kirin Co Lt, personal fees from Lexicon, personal fees from Lilly, personal fees from Lycera Biotech, personal fees from Merck, from Mesoblast Pharma, grants and personal fees from Millenium, personal fees from Nektar, personal fees from Nestles, personal fees from Novartis, personal fees from NovoNordisk, grants and personal fees from Pfizer, personal fees from Prometheus Therapeutics \& Diagnostics, personal fees from Protagonist, grants and personal fees from Receptos, personal fees from Salix, personal fees from Shire, personal fees from Sigmoid Pharma, personal fees from Synergy Pharma Inc, personal fees from Takeda, personal fees from Teva Pharma, personal fees from TiGenix, grants and personal fees from Tillotts, grants and personal fees from UCB, personal fees from Vertex Pharma, personal fees from VHsquared Ltd, personal fees from Warner-Chilcott, personal fees from Wyeth, personal fees from Zealand, personal fees from Zyngenia, outside the submitted work.

Ethics approval The study was approved by the Health Sciences Research Ethics Board at The University of Western Ontario.

Provenance and peer review Not commissioned; externally peer reviewed.

Data sharing statement Potential for data sharing can be discussed with study investigators.

Open Access This is an Open Access article distributed in accordance with the Creative Commons Attribution Non Commercial (CC BY-NC 4.0) license, which permits others to distribute, remix, adapt, build upon this work noncommercially, and license their derivative works on different terms, provided the original work is properly cited and the use is non-commercial. See: http:// creativecommons.org/licenses/by-nc/4.0/

\section{REFERENCES}

1. Vos $T$, Flaxman AD, Naghavi M, et al. Years lived with disability (YLDs) for 1160 sequelae of 289 diseases and injuries 1990-2010: 
a systematic analysis for the Global Burden of Disease Study 2010. Lancet 2012;380:2163-96.

2. Lawrence RC, Felson DT, Helmick CG, et al. Estimates of the prevalence of arthritis and other rheumatic conditions in the United States. Part II. Arthritis Rheum 2008;58:26-35.

3. Englund M, Roemer FW, Hayashi D, et al. Meniscus pathology, osteoarthritis and the treatment controversy. Nat Rev Rheumatol 2012;8:412-19.

4. Felson DT. Clinical practice. Osteoarthritis of the knee. N Engl J Med 2006;354:841-8.

5. McAlindon TE, Bannuru RR, Sullivan MC, et al. OARSI guidelines for the non-surgical management of knee osteoarthritis. Osteoarthritis Cartilage 2014;22:363-88.

6. Jevsevar DS, Brown GA, Jones DL, et al. The American Academy of Orthopaedic Surgeons evidence-based guideline on: treatment of osteoarthritis of the knee, 2nd edition. J Bone Joint Surg Am 2013;95:1885-6.

7. Fernandes L, Hagen K, Bijlsma J, et al, European League Against Rheumatism (EULAR). EULAR recommendations for the non-pharmacological core management of hip and knee osteoarthritis. Ann Rheum Dis 2013;72:1125-35.

8. Hochberg M, Altman R, April K, et al. American College of Rheumatology 2012 Recommendations for the use of nonpharmacologic and pharmacologic therapies in osteoarthritis of the hand, hip, and knee. Arthritis Care Res (Hoboken) 2012:64:465-74.

9. National Institute for Health and Care Excellence. Osteoarthritis. GC177. NICE, 2014.

10. Kirkley A, Birmingham TB, Litchfield RB, et al. A randomized trial of arthroscopic surgery for osteoarthritis of the knee. $N$ Engl J Med 2008;359:1097-107.

11. Moseley JB, O'Malley K, Petersen NJ, et al. A controlled trial of arthroscopic surgery for osteoarthritis of the knee. N Engl J Med 2002;347:81-8.

12. Katz JN, Brophy $\mathrm{RH}$, Chaisson $\mathrm{CE}$, et al. Surgery versus physical therapy for a meniscal tear and osteoarthritis. $N$ Engl J Med 2013;368:1675-84.

13. Herrlin S, Hallander M, Wange $P$, et al. Arthroscopic or conservative treatment of degenerative medial meniscal tears: a prospective randomized trial. Knee Surg Sports Traumatol Arthrosc 2007;15:393-401

14. Yim J-H, Seon J-K, Song E-K, et al. A Comparative study of meniscectomy and nonoperative treatment for degenerative horizontal tears of the medial meniscus. Am J Sports Med 2013;41:1565-70.

15. Gauffin $\mathrm{H}$, Tagesson $\mathrm{S}$, Meunier A, et al. Knee arthroscopic surgery is beneficial to middle-aged patients with meniscal symptoms: a prospective, randomised, single-blinded study. Osteoarthritis Cartilage 2014;22:1808-16.

16. Sihvonen R, Paavola M, Malmivaara A, et al. Arthroscopic partial meniscectomy versus sham surgery for a degenerative meniscal tear. N Engl J Med 2013;369:2515-24.

17. Thorlund JB, Juhl CB, Roos EM, et al. Arthroscopic surgery fo degenerative knee: systematic review and meta-analysis of benefits and harms. BMJ 2015;350:h2747.

18. Khan M, Evaniew N, Bedi A, et al. Arthroscopic surgery for degenerative tears of the meniscus: a systematic review and meta-analysis. CMAJ 2014;186:1057-64.

19. Canadian Institute for Health Information. Health Care in Canada 2010. 2010 Dec; Ottawa Ontario, Canada. (CIHI 2010) Report No: ISBN 978-1-55645-855-8.

20. Kim S, Bosque J, Meehan JP, et al. Increase in outpatient knee arthroscopy in the United States: a comparison of National Surveys of Ambulatory Surgery, 1996 and 2006. J Bone Joint Surg Am 2011;93:994-1000.

21. Howard D, Brophy R, Howell S. Evidence of no benefit from knee surgery for osteoarthritis led to coverage changes and is linked to decline in procedures. Health Aff 2012;31:2242-9.

22. Dhawan A, Mather R, Karas V, et al. An epidemiologic analysis of clinical practice guidelines for non-arthroplasty treatment of osteoarthritis of the knee. Arthroscopy 2014;30:65-71.

23. Holmes R, Moschette W, Martin B, et al. Effect of evidence and changes in reimbursement on the rate of arthroscopy for osteoarthritis. Am J Sports Med 2013;41:1039-43.

24. Mattila VM, Sihvonen R, Paloneva J, et al. Changes in rates of arthroscopy due to degenerative knee disease and traumatic meniscal tears in Finland and Sweden. Acta Orthop 2015;86:1-7.

25. Hamilton DF, Howie CR. Knee arthroscopy: influence of systems for delivering healthcare on procedure rates. BMJ 2015;351:h4720.

26. Thorlund JB, Hare KB, Lohmander LS. Large increase in arthroscopic meniscus surgery in the middle-aged and older population in Denmark from 2000 to 2011. Acta Orthop 2014:85:287-92.

27. Katz JN, Losina E. Arthroscopic partial meniscectomy for degenerative tears: where do we stand? Osteoarthritis Cartilage 2014:22:1749-51.

28. Elattrache N, Lattermann $\mathrm{C}$, Hannon M, et al. New England journa of medicine article evaluating the usefulness of meniscectomy is flawed. Arthroscopy 2014;30:542-3.

29. Carr A. Arthroscopic surgery for degenerative knee: overused, ineffective, and potentially harmful. BMJ 2015;350:h2983.

30. Losina $E$, Dervan $E E$, Paltiel $A D$, et al. Defining the value of future research to identify the preferred treatment of meniscal tear in the presence of knee osteoarthritis. PLoS ONE 2015;10:e0130256.

31. Krych AJ, Carey JL, Marx RG, et al. Does arthroscopic knee surgery work? Arthroscopy 2014;30:544-5.

32. Lubowitz JH, Appleby D. Cost-effectiveness analysis of the most common orthopaedic surgery procedures: knee arthroscopy and knee anterior cruciate ligament reconstruction. Arthroscopy 2011;27:1317-22.

33. Lorig K, Fries J. The arthritis helpbook: a tested self-management program for coping with arthritis and fibromyalgia. 5th edn. New York: Persues Books, 2000.

34. Hochberg MC, Altman RD, April KT, et al. Recommendations for the medical management of osteoarthritis of the hip and knee: 2000 update. American College of Rheumatology Subcommittee on Osteoarthritis Guidelines. Arthritis Rheum 2000;43:1905-15.

35. Bellamy N, Buchanan WW, Goldsmith $\mathrm{CH}$, et al. Validation study of WOMAC: a health status instrument for measuring clinically important patient relevant outcomes to antirheumatic drug therapy in patients with osteoarthritis of the hip or knee. J Rheumatol 1988; 15:1833-40.

36. Ehrich EW, Davies GM, Watson DJ, et al. Minimal perceptible clinical improvement with the Western Ontario and McMaste Universities osteoarthritis index questionnaire and global assessments in patients with osteoarthritis. J Rheumatol 2000;27:2635-41.

37. Davies GM, Watson DJ, Bellamy N. Comparison of the responsiveness and relative effect size of the western Ontario and McMaster Universities Osteoarthritis Index and the short-form Medical Outcomes Study Survey in a randomized, clinical trial of osteoarthritis patients. Arthritis Care Res 1999;12:172-9.

38. Kirkley A, Webster-Bogaert S, Litchfield R, et al. The effect of bracing on varus gonarthrosis. $J$ Bone Joint Surg Am 1999;81:539-48.

39. Drummond M, Sculpher M, Torrance G, et al. Methods for the economic evaluation of health care programmes. 3rd edn. New York: Oxford University Press, 2005.

40. Gold M, Siegel J, Russel L, et al. Cost-effectiveness in health and medicine. New York: Oxford University Press, 1996.

41. Torrance GW. Utility approach to measuring health-related quality of life. J Chronic Dis 1987;40:593-603.

42. Ontario Case Costing Initiative (OCCl). Version 7.1 Acute Inpatient Databases for fiscal year 2010/11. Toronto: Ministry of Health and Long-Term Care, 2013.

43. Ontario Schedule of Benefits. Physician services under the Health Insurance Act. 2013. Toronto: Ministry of Health and Long-Term Care, 2013.

44. Ontario Drug Benefit Formulary 2013. Ministry of Health and Long-Term Care. Toronto: Government of Ontario, Canada, 2013. https://www.healthinfo.moh.gov.on.ca/formulary/ (accessed Jan 2013)

45. Hoch JS, Briggs AH, Willan AR. Something old, something new, something borrowed, something blue: a framework for the marriage of health econometrics and cost-effectiveness analysis. Health Econ 2002;11:415-30.

46. Hoch JS, Rockx MA, Krahn AD. Using the net benefit regression framework to construct cost-effectiveness acceptability curves: an example using data from a trial of external loop recorders versus Holter monitoring for ambulatory monitoring of "community acquired" syncope. BMC Health Serv Res 2006:6:68.

47. Englund M, Roos EM, Roos HP, et al. Patient-relevant outcomes fourteen years after meniscectomy: influence of type of meniscal tear and size of resection. Rheumatology (Oxford) 2001;40:631-9.

48. Lohmander LS, Englund PM, Dahl LL, et al. The long-term consequence of anterior cruciate ligament and meniscus injuries: osteoarthritis. Am J Sports Med 2007;35:1756-69.

49. Bedi A, Kelly NH, Baad M, et al. Dynamic contact mechanics of the medial meniscus as a function of radial tear, repair, and partial meniscectomy. J Bone Joint Surg Am 2010;92:1398-408.

50. Brophy RH, Gray BL, Nunley RM, et al. Total knee arthroplasty after previous knee surgery: expected interval and the effect on patient age. J Bone Joint Surg Am 2014;96:801-5. 